\title{
Trade Agreements and the Nature of Price Determination
}

\section{Citation}

Antràs, Pol, and Robert W Staiger. 2012. "Trade Agreements and the Nature of Price Determination." American Economic Review 102 (3): 470-76. https://doi.org/10.1257/ aer.102.3.470.

\section{Permanent link}

http://nrs.harvard.edu/urn-3:HUL.InstRepos:37969487

\section{Terms of Use}

This article was downloaded from Harvard University's DASH repository, and is made available under the terms and conditions applicable to Other Posted Material, as set forth at http:// nrs.harvard.edu/urn-3:HUL.InstRepos:dash.current.terms-of-use\#LAA

\section{Share Your Story}

The Harvard community has made this article openly available.

Please share how this access benefits you. Submit a story.

Accessibility 


\title{
Trade Agreements and the Nature of Price Determination
}

\author{
By Pol Antràs and Robert W. Staiger*
}

The terms-of-trade theory of trade agreements holds that governments are attracted to trade agreements as a means of escape from a terms-of-trade-driven prisoner's dilemma (see Bagwell and Staiger 1999). One of the termsof-trade theory's most striking predictions is about the treatment of behind-the-border policy measures in trade agreements. According to this prediction, in the noncooperative Nash equilibrium from which countries would begin in the absence of a trade agreement, tariffs are set inefficiently high but behind-the-border policies are set at efficient levels. Hence, even in the context of a complex policy environment there is no need for member governments of a trade agreement to negotiate directly over the levels of their behind-the-border policies. Rather, according to the terms-of-trade theory, the fundamental problem for a trade agreement to solve is to prevent terms-of-trade manipulation and to thereby reduce tariffs and raise trade volumes, without introducing distortions into the unilateral choices of domestic tax/subsidy and regulatory policies as a result of the negotiated constraints on tariffs (see Bagwell and Staiger 2001). Importantly, this result holds for a wide variety of government preferences and has also been shown to hold in imperfectly competitive environments.

The terms-of-trade theory of trade agreements therefore provides strong support for "shallow" integration as the most direct means to solve the policy inefficiencies that would arise absent a trade agreement. Simply put, according to the terms-of-trade theory, negotiations over tariffs alone, coupled with an effective "market access preservation rule" that prevents governments

\footnotetext{
* Antràs: Harvard University, Cambridge, MA (e-mail: pantras@fas.harvard.edu); Staiger: University of Wisconsin, Madison, WI (e-mail: rstaiger@wisc.edu). We thank Kyle Bagwell, Arnaud Costinot, and Michele Ruta for helpful comments.

${ }^{\dagger}$ To view additional materials, visit the article page at http://dx.doi.org/10.1257/aer.102.3.470.
}

from subsequently manipulating their domestic policy choices to undercut the market access implications of their tariff commitments, can bring governments to the efficiency frontier. ${ }^{\mathrm{T}}$

In this paper, we show that the nature of international price determination can have important effects on this prediction of the terms-of-trade theory. In particular, while the terms-of-trade theory adopts the view that international prices are fully disciplined by market clearing conditions, we show here that support for shallow integration is overturned, and instead a need for "deep" integration is suggested-wherein direct negotiations occur over both border and behindthe-border policies - if international prices are determined through bargaining.

Our results are most closely related to those in Antràs and Staiger (forthcoming), where we focus on the potential for offshoring of specialized inputs to increase the prevalence of bargaining as a mechanism for international price determination, and where we argue that as such the recent rise in offshoring may present the World Trade Organization (WTO) with a profound institutional challenge. Here we abstract from the details of offshoring and consider instead foreign producers and domestic consumers of a final good that interact under different market structures and under different mechanisms of price determination. Our main result is that when foreign producers and domestic consumers must match and bargain over the terms of their exchange, and this bargaining is not fully disciplined by market clearing conditions, shallow integration can no longer achieve internationally efficient policies. Although the

\footnotetext{
${ }^{1}$ At a conceptual level, this resonates with the approach taken by the General Agreement on Tariffs and Trade (GATT) (and, to a lesser extent, by the WTO) to behind-the-border policies, wherein negotiations focus on tariff reductions as a means to expand market access, and where various GATT provisions (such as GATT's "nonviolation" clause) are then meant to protect the value of negotiated market access agreements against erosion by behind-the-border policies.
} 
simple models we develop below are special along several dimensions, in a longer version of this paper, Antràs and Staiger (2012), we show that our main results apply in much more general environments. We refer the reader to this longer paper for the derivations of our main results.

\section{Perfect Competition}

We consider first a two-country Home/Foreign partial-equilibrium perfectly competitive trade model in which Foreign (denoted with a “*”) exports a single good to Home. In particular, we assume that there is a measure $1 / 2$ of consumers at Home with demand $D(p)$, a measure $1 / 2$ of consumers in Foreign with demand $D\left(p^{*}\right)$, and a measure 1 of firms in Foreign with production technology $y^{*}=F\left(L^{*}\right)$, with $F^{\prime}\left(L^{*}\right)>0$, $F^{\prime \prime}\left(L^{*}\right)<0$, and Inada conditions holding. Finally, there is a measure $\Lambda$ of workers in each country that are paid a wage of 1 (with a numeraire good entering linearly into utility and closing our partial equilibrium model in the usual way).

We suppose that the Home government has an import tariff $\tau$, while the Foreign government has both an export tax $\tau^{*}$ and a labor subsidy $s^{*}$ (applied only to the export sector). All policies are defined in specific terms. Markets are integrated and so the wedge between foreign and domestic prices satisfies $p=p^{*}+\left(\tau+\tau^{*}\right)$ for nonprohibitive tariffs. Throughout, we assume that governments are social welfare maximizers, but none of our results depend on this.

The competitive production sector in Foreign hires labor to maximize profits and thus solves

$$
\hat{L}^{*}=\arg \max \left\{\pi^{*}=p^{*} F\left(L^{*}\right)-\left(1-s^{*}\right) L^{*}\right\},
$$

yielding the first-order condition $p^{*} F^{\prime}\left(\hat{L}^{*}\right)$ $=1-s^{*}$, and implying $\hat{L}^{*}\left(s^{*}, p^{*}\right)$, and hence $\hat{y}^{*}\left(s^{*}, p^{*}\right) \equiv F\left(\hat{L}^{*}\left(s^{*}, p^{*}\right)\right)$. The international market clearing condition is then

$$
\hat{y}^{*}\left(s^{*}, p^{*}\right)=D\left(p^{*}+\left(\tau+\tau^{*}\right)\right) / 2+D\left(p^{*}\right) / 2,
$$

determining the market clearing foreign price $\hat{p}^{*}\left(s^{*}, \tau+\tau^{*}\right)$. We then have $\hat{p}\left(s^{*}, \tau+\tau^{*}\right)$ $\equiv \hat{p}^{*}\left(s^{*}, \tau+\tau^{*}\right)+\left(\tau+\tau^{*}\right)$. Notice that the foreign and domestic local prices are functions of the sum of tariffs only, as are $\hat{L}^{*}$ and $\hat{y}^{*}$. We will use this property shortly when we solve for the efficient tariffs.
Welfare levels are given by the sum of consumer and producer surplus and net tax revenues (in addition to labor income $\Lambda$ ):

$$
\begin{aligned}
W= & \Lambda+(1 / 2) \int_{\hat{p}}^{\bar{p}} D(p) d p+\tau D(\hat{p}) / 2 ; \\
W^{*}= & \Lambda+(1 / 2) \int_{\hat{p}^{*}}^{\bar{p}} D(p) d p+\pi^{*}\left(s^{*}, \hat{p}^{*}\right) \\
& +\tau^{*} D(\hat{p}) / 2-s^{*} \hat{L}^{*}\left(s^{*}, \hat{p}^{*}\right),
\end{aligned}
$$

where we have suppressed the dependence of $\hat{p}$ and $\hat{p}^{*}$ on $s^{*}$ and $\left(\tau+\tau^{*}\right)$ to save space.

We consider first the efficient policies, which maximize $W^{W}=W+W^{*}$. Letting $T \equiv\left(\tau+\tau^{*}\right)$, it is straightforward to show that $W^{W}$ is only a function of the aggregate trade tax $T$ and the labor subsidy $s^{*}$. The efficient choice of these instruments must then satisfy the firstorder conditions $\partial W^{W} / \partial T=0$ and $\partial W^{W} / \partial s^{*}$ $=0$, which yield

$$
T^{e}=0, \quad s^{* e}=0 .
$$

That the efficient policies in this setting correspond to laissez-faire should come as no surprise, as there are no frictions in our competitive model.

The noncooperative Nash policies are determined by the three first-order conditions $\partial W^{*} / \partial \tau^{*}=0, \partial W^{*} / \partial s^{*}=0$, and $\partial W / \partial \tau=0$. Manipulating the first two first-order conditions, which determine the Foreign best-response policies to any Home tariff, yields

$$
\tau^{* R}=\hat{p} / \eta_{M}, \quad s^{* R}=0,
$$

where $\eta_{M}$ is the elasticity of Home import demand defined positively and so $\tau^{* R}$ is the Johnson optimal terms-of-trade-manipulating export tax defined for a specific tariff. Turning to the Home best-response tariff, the associated first-order condition can be manipulated to yield

$$
\tau^{R}=\hat{p}^{*} / \eta_{E}^{*},
$$

where $\eta_{E}^{*}$ is the elasticity of foreign export supply and so $\tau^{R}$ is the Johnson optimal import tariff defined for a specific tariff.

Nash policies are $\tau^{N}=\hat{p}^{*} / \eta_{E}^{*}, \tau^{* N}=\hat{p} / \eta_{M}$, and $s^{* N}=0$ (where all prices and elasticities are evaluated at the Nash policies). Notice that the 
sum of the Nash tariffs is strictly positive, and so Nash tariffs are inefficiently high $\left(T^{N}>T^{e}\right)$, but the Foreign Nash subsidy is set at its efficient level $\left(s^{* N}=s^{* e}\right)$. As a consequence, the fundamental inefficiency for a trade agreement to correct in this setting is the unilateral incentive for each government to manipulate the terms of trade with its tariff choice. But Foreign could in principle use both $\tau^{*}$ and $s^{*}$ to alter its terms of trade. Why, then, is $s^{*}$ left undistorted from its internationally efficient level in the noncooperative Nash equilibrium? The simple reason is that the tariff is the first-best instrument for manipulating the terms of trade in this environment, and hence with the Foreign Nash tariff set to achieve this purpose, there is no need for Foreign to distort any other policy choices to engage in termsof-trade manipulation.

The fact that the Foreign Nash subsidy is set at its efficient level does not mean that the two countries could achieve the efficiency frontier by simply committing to reduce their tariffs from Nash levels to free trade, because such an agreement would induce Foreign to then alter its subsidy from the efficient level of zero as a partial substitute for its now-constrained tariff. Hence, while it is true that $s^{* N}$ is set at the efficient level, this does not imply that a simple agreement to eliminate tariffs can move countries from the inefficient Nash equilibrium to the efficiency frontier.

Suppose, though, that the two countries begin at the Nash policies and negotiate a tariff agreement in which Home agrees to eliminate its tariff and Foreign agrees to eliminate its tariff, and in addition Foreign agrees to a "market access preservation" constraint, according to which it will not make policy adjustments in the future that alter the trade volume implied by the two countries' tariff commitments and the Foreign subsidy policy in place at the time of their negotiation (i.e., the subsidy level $s^{* N}=0$ ). Can the efficiency frontier be achieved with this form of "shallow" integration?

The answer to this question hinges on the policies Foreign will choose in light of the market-access preservation constraint. As preserving $\hat{p}$ with adjustments in Foreign policies is necessary and sufficient for preserving equilibrium trade volume in this environment, the market-access preservation constraint can be written as changes in $s^{*}$ that are accompanied by changes in $\tau^{*}$ that leave $\hat{p}$ unchanged, or $d \tau^{*} / d s^{*}=-\left(d \hat{p} / d s^{*}\right) /\left(d \hat{p} / d \tau^{*}\right)$. Facing this market-access preservation constraint subsequent to its tariff negotiations with Home, the Foreign choices of $\tau^{*}$ and $s^{*}$ will then satisfy the following first-order condition:

$$
\frac{d W^{*}}{d s^{*}}=\frac{\partial W^{*}}{\partial s^{*}}-\frac{\partial W^{*}}{\partial \tau^{*}} \frac{d \hat{p} / d s^{*}}{d \hat{p} / d \tau^{*}}=0,
$$

with $W^{*}$ evaluated at $\tau=0$. Straightforward manipulations establish that this equation can only hold if $s^{*} R=0$. Hence, with $\tau=0$, the market access constraint will induce Foreign to select the combination $\tau^{*}=0$ and $s^{*}=0$ to meet the market access constraint and deliver the efficient trade volume, so that "shallow" negotiations designed in this way will achieve the efficiency frontier.

\section{Imperfect Competition}

In this section, we illustrate the robustness of our main result above to the introduction of imperfect competition. This will serve as an intermediate step in isolating the role that price determination plays in our results, given that our matching model below inherently features (ex post) market power. For that purpose, suppose now that production in Foreign is undertaken by a single monopoly firm, and that the Home and Foreign markets are segmented so that the Foreign monopolist is unconstrained in its ability to set different prices in the Home and Foreign market (see Antràs and Staiger 2012 for alternative models of imperfect competition). The quantity produced by the Foreign monopolist for local (Foreign) sales is denoted by $x^{*}$, while that produced for export to the Home market is denoted by $x$, with total Foreign production given by $y^{*}=x^{*}+x$. Market clearing in each market determines the local price at which the Foreign monopolist's chosen quantity sells:

$$
\begin{gathered}
x=D(p) / 2 \Rightarrow p=P(x), \\
x^{*}=D\left(p^{*}\right) / 2 \Rightarrow p^{*}=P\left(x^{*}\right) .
\end{gathered}
$$

The Foreign monopolist production levels are determined by maximizing profits:

$$
\begin{aligned}
\pi^{*}= & {\left[P(x)-\left(\tau+\tau^{*}\right)\right] \cdot x+P\left(x^{*}\right) \cdot x^{*} } \\
& -\left(1-s^{*}\right) \cdot L^{*}\left(x+x^{*}\right),
\end{aligned}
$$


which results in $\hat{x}\left(s^{*}, \tau+\tau^{*}\right)$ and $\hat{x}^{*}\left(s^{*}, \tau+\tau^{*}\right)$. With these in hand, one can compute the monopolist's labor demand $\hat{L}^{*}\left(s^{*}, \tau+\tau^{*}\right)$ $\equiv L^{*}\left(\hat{x}\left(s^{*}, \tau+\tau^{*}\right)+\hat{x}^{*}\left(s^{*}, \tau+\tau^{*}\right)\right)$, and equilibrium domestic and foreign local prices $\hat{p}$ $\equiv P\left(\hat{x}\left(s^{*}, \tau+\tau^{*}\right)\right)$ and $\hat{p}^{*} \equiv P\left(\hat{x}^{*}\left(s^{*}, \tau+\tau^{*}\right)\right)$.

Welfare levels are given by the sum of consumer surplus, profits, and net tax revenues:

$$
\begin{aligned}
W= & \Lambda+(1 / 2) \int_{\hat{p}}^{\bar{p}} D(p) d p+\tau \hat{x} ; \\
W^{*}= & \Lambda+(1 / 2) \int_{\hat{p}^{*}}^{\bar{p}} D(p) d p+\pi^{*} \\
& +\tau^{*} \hat{x}-s^{*} \hat{L}^{*},
\end{aligned}
$$

where we suppress arguments on the right-hand side of each expression for simplicity.

Efficient policies maximize $W^{W}=W+W^{*}$, which are again functions of only the sum of tariffs and the Foreign labor subsidy. Recalling that $T \equiv\left(\tau+\tau^{*}\right)$, the efficient tariffs $T$ must then satisfy $\partial W^{W} / \partial T=0$ and the efficient Foreign subsidy $s^{*}$ must satisfy $\partial W^{W} / \partial s^{*}=0$. Together with the first-order conditions for profit maximization and the market clearing conditions, these two first-order conditions can be manipulated to yield $T^{e}=0$ and $s^{* e}=-1 / 2 D\left(\hat{p}^{*}\right) \cdot \hat{p}^{* \prime} / L^{* \prime}$ where primes denote derivatives, which by the firstorder conditions for profit maximization implies $\hat{p}=\hat{p}^{*}=L^{*}$. Hence, under the efficient policies, price in each market is equated to marginal cost. Finally, using the market clearing condition to derive $\hat{p}^{* \prime}=2 / D^{\prime}\left(\hat{p}^{*}\right)$, we may rewrite the efficient policies as

$$
T^{e}=0, \quad s^{* e}=1 / \eta_{D}^{*}
$$

with $\eta_{D}^{*}$ the elasticity of Foreign demand defined positively and evaluated at the efficient policies (where Foreign and Home demand elasticities are equal). Evidently, the efficient Foreign production subsidy addresses the Foreign monopoly distortion, and there is no role for tariffs.

The noncooperative Nash policies are determined by the three first-order conditions $\partial W^{*} / \partial \tau^{*}=0, \partial W^{*} / \partial s^{*}=0$, and $\partial W / \partial \tau=0$. As before, we begin with the first two first-order conditions, which determine the Foreign best-response policies to any Home tariff. Using the first-order condition for profit maximization and the market clearing conditions, these two conditions can be manipulated to yield

$$
\tau^{* R}=\hat{p}^{*} / \eta_{D}^{*}, \quad s^{* R}=1 / \eta_{D}^{*},
$$

where recall that $\eta_{D}^{*}$ is the Foreign elasticity of demand defined positively. The best-response tariff of Foreign thus corrects for the Foreign monopoly distortion faced by consumers in the Foreign market (reducing the Foreign local price with an export tax $\left.\hat{p}^{*} / \eta_{D}^{*}\right)$ but otherwise leaves undistorted the Foreign monopoly exporter's incentive to exploit its monopoly power in the Home market. And notice that the formula for the best-response Foreign subsidy (though not necessarily the level of the subsidy) is identical to that for the efficient Foreign subsidy. Turning to the Home best-response tariff, using the market clearing conditions and the fact that $\hat{p}^{\prime}=2 / D^{\prime}(\hat{p})$, the associated first-order condition can be manipulated to yield

$$
\tau^{R}=-\hat{x} /(d \hat{x} / d \tau)-\hat{p} / \eta_{D}
$$

where $\eta_{D}$ is the elasticity of Home demand defined positively. The best-response Home tariff serves two roles: first, it extracts rent from the Foreign monopolist with a $\operatorname{tax}(-\hat{x} /(d \hat{x} / d \tau))$ on imports; and second, this incentive to tax imports is tempered by the incentive to correct for the Foreign monopoly distortion of Home consumption with an offsetting import subsidy $\left(-\hat{p} / \eta_{D}\right)$. As is well known, whether the bestresponse Home tariff is positive or negative depends on the curvature properties of demand.

Again, Nash policies are the mutual bestresponse policies: $\tau^{N}=-\hat{x} /(d \hat{x} / d \tau)-\hat{p} / \eta_{D}$, $\tau^{* N}=\hat{p}^{*} / \eta_{D}^{*}$ and $s^{* N}=1 / \eta_{D}^{*}$ where all prices, derivatives, and elasticities are evaluated at the Nash policies. As with the competitive model above, with a Foreign monopoly the sum of the Nash tariffs is strictly positive, and so Nash tariffs are inefficiently high $\left(T^{N}>T^{e}\right)$. And while the level of the Foreign Nash subsidy will in general differ from the efficient subsidy level because the elasticity of Foreign demand $\eta_{D}^{*}$ is evaluated at different points on the Foreign demand curve across Nash and efficient policies, the fact that the two expressions are identical implies that the Foreign Nash subsidy is efficient conditional on 
the Nash trade volume, a feature which extends to the Foreign best-response subsidy and which we next exploit.

Suppose then that Home and Foreign begin at the Nash policies and negotiate a tariff agreement in which Home agrees to eliminate its tariff and Foreign agrees to set its tariff at a level $\bar{\tau}^{*}$ such that $\hat{x}\left(s^{* N}, 0+\bar{\tau}^{*}\right)=\hat{x}\left(s^{* e}, T^{e}\right)$, and in addition Foreign agrees to a market-access preservation constraint, according to which it will not make policy adjustments in the future that alter the trade volume implied by the two countries' tariff commitments and the Foreign subsidy policy in place at the time of their negotiation (i.e., $s^{* N}$ ). Is this form of shallow integration sufficient to achieve the efficiency frontier?

As before, the answer to this question hinges on the policies that Foreign will choose in light of the market access preservation constraint. In this environment, the market-access preservation constraint can be written as changes in $s^{*}$ that are accompanied by changes in $\tau^{*}$ that hold $\hat{x}$ (or alternatively, $\hat{p}$ ) constant: $d \tau^{*} / d s^{*}$ $=-\left(d \hat{x} / d s^{*}\right) /\left(d \hat{x} / d \tau^{*}\right)$. Facing this market access constraint, the Foreign choices of $\tau^{*}$ and $s^{*}$ will then satisfy the first-order condition:

$$
\frac{d W^{*}}{d s^{*}}=\frac{\partial W^{*}}{\partial s^{*}}-\frac{\partial W^{*}}{\partial \tau^{*}} \frac{d \hat{x} / d s^{*}}{d \hat{x} / d \tau^{*}}=0,
$$

with $W^{*}$ evaluated at $\tau=0$. Straightforward algebra indicates that this condition can only hold if $s^{* R}=s^{* e}$ and $\tau^{* R}=0$. Hence, with negotiations setting $\tau=0$ and $\tau^{*}=\bar{\tau}^{*}$, the market-access preservation constraint will induce Foreign to select the combination $\tau^{*}=0$ and $s^{*}=s^{* e}$ to meet the market-access constraint and deliver the efficient trade volume, so that "shallow" negotiations designed in this way are indeed sufficient to place countries on the efficiency frontier.

\section{Matching}

We now depart from a price mechanism fully disciplined by aggregate market clearing, and suppose instead that the price at which goods are exchanged between buyers and sellers is determined through bilateral bargaining. Specifically, we assume that the measure 1 of consumers is each randomly matched with the measure 1 of producers and there is no possibility of rematching, so that the outside option of the agents is $0 .{ }^{2}$ After learning their match, producers produce an amount of $x$ with the production function $F(L)$ in anticipation of the payoff they will obtain from bargaining. With the cost of producing $x$ sunk at the time of bargaining, and with utility given by the increasing and concave function $u(x)$, the consumer and the producer Nash bargain over the ex post surplus, with producers capturing a share $\alpha \in(0,1)$ of surplus.

Suppose that an international match is formed and then Foreign sellers take their good to the Home country. In such a case, tariff costs are not sunk at the time of bargaining, and the ex post surplus over which the parties negotiate is $S\left(L, \tau+\tau^{*}\right) \equiv u(F(L))-\left(\tau+\tau^{*}\right) F(L)$. The labor $L$ hired by Foreign producers selling at Home is then determined by maximizing $\alpha S\left(L, \tau+\tau^{*}\right)-\left(1-s^{*}\right) L$, which optimizing over $L$ defines $\hat{L}\left(s^{*}, \tau+\tau^{*}\right)$ and thus trade volume $F\left(\hat{L}\left(s^{*}, \tau+\tau^{*}\right)\right)$ according to

(1) $\alpha\left[u^{\prime}(F(\hat{L}))-\left(\tau+\tau^{*}\right)\right] F^{\prime}(\hat{L})=1-s^{*}$.

By contrast, for Foreign producers selling locally to consumers in the Foreign country and creating Foreign local pairs, labor demand $\hat{L}^{*}\left(s^{*}\right)$ is determined by

$$
\alpha u^{\prime}\left(F\left(\hat{L}^{*}\right)\right) F^{\prime}\left(\hat{L}^{*}\right)=1-s^{*} .
$$

Home welfare is composed of the Home share of bargaining surplus from the measure $1 / 2$ of international matches, plus the tariff revenue associated with these matches:

$$
\begin{aligned}
W= & \Lambda+\frac{1}{2}(1-\alpha)\left[u(F(\hat{L}))-\left(\tau+\tau^{*}\right) F(\hat{L})\right] \\
& +(1 / 2) \tau F(\hat{L}),
\end{aligned}
$$

where we suppress the dependence of $\hat{L}$ on $s^{*}$ and $\left(\tau+\tau^{*}\right)$ for ease of notation. Foreign welfare is composed of the bargaining surplus from the $1 / 2$ Foreign local matches minus the associated labor subsidy, the Foreign share of bargaining surplus from the $1 / 2$ international

\footnotetext{
${ }^{2}$ In Antràs and Staiger (2012), we establish the robustness of our results to less extreme matching models where: (i) if negotiations break down, agents can resort to a secondary market; (ii) producers can choose in which market to search for matches; and (iii) production decisions are made before matching occurs.
} 
matches minus the associated labor subsidy, plus tariff revenue associated with international matches:

$$
\begin{aligned}
W^{*}= & \Lambda+\frac{1}{2} u\left(F\left(\hat{L}^{*}\right)\right)-\frac{1}{2} \hat{L}^{*}+\frac{1}{2} \tau^{*} F(\hat{L}) \\
& +\frac{1}{2} \alpha\left[u(F(\hat{L}))-\left(\tau+\tau^{*}\right) F(\hat{L})\right]-\frac{1}{2} \hat{L},
\end{aligned}
$$

where again we suppress the dependence of $\hat{L}^{*}$ on $s^{*}$ and of $\hat{L}$ on $s^{*}$ and $\left(\tau+\tau^{*}\right)$ for ease of notation.

Efficient policies maximize world welfare $W^{W}=W+W^{*}$, which does not depend directly on policies because their direct effect in this environment is simply to shift surplus across agents and such surplus-shifting itself has no bearing on world welfare. As a result, the impact of policies on world welfare travels entirely through their impact on the labor decisions $\hat{L}$ and $\hat{L}^{*}$, and recall also that labor decisions only depend on $s^{*}$ and (in the case of $\hat{L}$ ) the sum of tariffs $T=\tau+\tau^{*}$.

The efficient tariffs $T$ and labor subsidy $s^{*}$ must satisfy the first-order conditions $\partial W^{W} / \partial T$ $=0$ and $\partial W^{W} / \partial s^{*}=0$, which using (1) and (2) can be manipulated to yield

$$
T^{e}=0, \quad s^{* e}=1-\alpha .
$$

Efficient intervention requires a Foreign labor subsidy to resolve the underinvestment in $L$, but there is no role for tariffs.

The noncooperative Nash policies are determined by the three first-order conditions $\partial W^{*} / \partial \tau^{*}=0, \partial W^{*} / \partial s^{*}=0$, and $\partial W / \partial \tau=0$. Using (1) and (2), these first-order conditions can be manipulated to show that

$$
s^{* N}>1-\alpha, \quad \tau^{N}+\tau^{* N}>0 .
$$

Hence, as in both the competitive and the monopoly models considered above, Nash tariffs are inefficiently high $\left(T^{N}>T^{e}\right)$. And like the monopoly model, the level of the Nash Foreign subsidy differs from the efficient level. But unlike in the monopoly model and as we next confirm, the Nash (or best-response) Foreign subsidy is not set efficiently even conditional on the Nash (or best-response) trade volume.
To show this more formally, we return again to our thought experiment in which we set $\tau=0$ and in effect allow Foreign to optimize over the mix of $\tau^{*}$ and $s^{*}$ as long as equilibrium trade volumes correspond to those of the efficient policies. Recall that trade volumes are given by $F\left(\hat{L}\left(s^{*}, \tau+\tau^{*}\right)\right)$ and hence determined by $\hat{L}\left(s^{*}, \tau+\tau^{*}\right)$ as defined by (1), which implies that trade volumes are constant as long as changes in $\tau^{*}$ and $s^{*}$ satisfy $d \tau^{*} / d s^{*}$ $=-\left(d \hat{L} / d s^{*}\right) /\left(d \hat{L} / d \tau^{*}\right)$. Facing this market access constraint, the Foreign choices of $\tau^{*}$ and $s^{*}$ will then satisfy the following first-order condition (with $W^{*}$ evaluated at $\tau=0$ ):

$$
\frac{d W^{*}}{d s^{*}}=\frac{\partial W^{*}}{\partial s^{*}}-\frac{\partial W^{*}}{\partial \tau^{*}} \frac{d \hat{L} / d s^{*}}{d \hat{L} / d \tau^{*}}=0,
$$

which can be simplified to yield

$\frac{1}{2}\left[u^{\prime}\left(F\left(\hat{L}^{*}\right)\right) F^{\prime}\left(\hat{L}^{*}\right)-1\right] \frac{d \hat{L}^{*}}{d s^{*}}=-\frac{1-\alpha}{\alpha} \frac{F(\hat{L})}{F^{\prime}(\hat{L})}$.

Because $d \hat{L}^{*} / d s^{*}>0$, this condition implies that $s^{* R}$ must ensure that $u^{\prime}\left(F\left(\hat{L}^{*}\right)\right) F^{\prime}\left(\hat{L}^{*}\right)<1$, which in turn from (2) implies $s^{* R}>s^{* e}=1-\alpha$. Thus, despite the presence of a market access preservation constraint, "shallow" negotiations designed in this way will not achieve the efficiency frontier in the current environment, because such negotiations cannot fully eliminate terms-of-trade manipulation.

This result can be further understood by defining the "world"/exporter per-unit price at which the goods are exchanged in the bilateral bargain. In this environment, the world price is given by $\hat{p}^{w}=\alpha u(F(\hat{L})) / F(\hat{L})+$ $(1-\alpha) \tau^{*}-\alpha \tau$, but it is then clear that the increases in $s^{*}$ and $\tau^{*}$ that hold $\hat{L}$ (and hence trade volume) fixed will nevertheless raise $\hat{p}^{w}$ and hence confer the benefit of a terms-of-trade improvement on Foreign.

In sum, and in contrast to the two models analyzed above where international prices are fully disciplined by aggregate market-clearing conditions, when international prices are instead determined by bargaining, "deep" integration-under which both trade and domestic policies are the direct focus of negotiationsmay be required to achieve the efficiency frontier. 


\section{REFERENCES}

Antràs, Pol, and Robert W. Staiger. Forthcoming. "Offshoring and the Role of Trade Agreements." American Economic Review.

Antràs, Pol, and Robert W. Staiger. 2012. "Trade Agreements and the Nature of Price Determination." Unpublished.
- Bagwell, Kyle, and Robert W. Staiger. 1999. "An Economic Theory of GATT." American Economic Review 89 (1): 215-48.

- Bagwell, Kyle, and Robert W. Staiger. 2001. "Domestic Policies, National Sovereignty and International Economic Institutions." Quarterly Journal of Economics 116 (2): 519-62. 